\title{
От восприятия перемен - к изменению социального поведения
}

\author{
Д.Л. КОНСТАНТИНОВСКИЙ*, Е.С. ПОПОВА**
}

\begin{abstract}
*Давид Львович Константиновский - доктор социологических наук, руководитель отдела социологии образования, Институт социологии ФНИСЦ РАН, Москва, Россия, scan21@mail.ru,_https://orcid.org/0000-0003-3316-0644

**Екатерина Сергеевна Попова - кандидат социологических наук, ведущий научный сотрудник, Институт социологии ФНИСЦ РАН, Москва, Россия, espopova@isras.ru, https://orcid.org/0000-0002-9808-3152

Цитирование: Константиновский Д.Л., Попова Е.С. (2022) От восприятия перемен - к изменению социального поведения // Мир России. Т. 31. № 1. С. 6-24. DOI: 10.17323/1811-038X-2022-31-1-6-24
\end{abstract}

\begin{abstract}
Аннотация
Статья посвящена анализу изменений в образовательных и профессиональных траекториях как молодого, так и более стариих поколений. Рассмотрение эмпирических материалов предваряет краткий обзор поисков, предпринимаемых в этом направлении. Авторское исследование основано на интервью с респондентами разных возрастов, которые ретроспективно оценивают свой жизненный опыт. Наиболее существенной характеристикой анализируемых биографий является нелинейность образовательных и профессиональных траекторий, связанная с отношением респондентов к социальной мобильности и неравенству в доступности образования. Респондент склонялся к одному из видов реакиии на специффику личной ситуации - стратегии стабильности либо стратегии мобильности, а модель соичиального поведения определяла его проактивность. Разнообразие и гибкость выбора дальнейшего пути в значительной степени становились возможны благодаря относительной открытости отечественной системы профессионального образования. Предлагается метафора «квест» применительно к образовательным и профессиональным траекториям, подчеркивающая необходимость на каждом этапе их формирования распознавать новые обстоятельства реальности и решать возникающие при этом задачи. Характер рассматриваемых изменений указывает на то, что они могут не только повлечь за собой перемень в сфере образования, но и иметь последствия для формирования человеческого капитала, а также определят новый мейнстрим в социологии образования.
\end{abstract}

Ключевые слова: образование, образовательные траектории, профессиональные траектории, среднее профессиональное образование, высшее образование, рынок труда, сочиальная мобильность, неравенство

Статья поступила в редакцию в июне 2021 г. 


\section{Введение}

В последние десятилетия в образовательных и профессиональных траекториях как молодого, так и более старших поколений происходили изменения, которые фиксировались отдельными исследовательскими проектами, но не становились предметом широкого научного и общественного интереса. Мейнстрим в социологии образования естественным образом совпадал со сложившимися представлениями об ориентациях, предпочтениях и мотивах в построении образовательной и профессиональной карьеры: убежденность в том, что высшее образование является максимально желанной точкой образовательного пути, десятилетиями была общепринятой и не оспаривалась в российском общественном мнении. Именно высшее образование и пути к нему в отечественной науке были и до настоящего времени остаются наиболее часто представленным предметом социологических исследований.

Однако за изменениями в привлекательности профессий [Саганенко $u d p$. 2015] в новых условиях последовали и перемены в мотивации к образованию (обусловленные также изменениями в ситуации), а затем, как их проявление, и в образовательных и профессиональных траекториях. Они стали предметом изучения в Отделе социологии образования Института социологии ФНИСЦ РАН в рамках анализа профессиональных ориентаций и траекторий в сфере образования и на рынке труда. Эмпирические результаты были отображены в ряде публикаций [Константиновский и др. 2013; Константиновский и др. 2015, с. 98-122, 184-209]; по мере того, как формировалось осознание значимости изменений, начала подтверждаться их устойчивость, а к концу десятилетия обсуждение происходящего вышло за пределы научных дискуссий.

Статья предлагается как продолжение цикла публикаций полученных к настоящему времени результатов проекта по изучению масштабных перемен в отношении к образованию, их причин и следствий ${ }^{1}$. Стратегия проекта определяется его нацеленностью на отслеживание динамики значимых изменений. Его нынешняя стадия строится как сочетание трех блоков - статистического блока, количественного социологического исследования и исследования качественными методами. В предыдущей статье были представлены основные материалы статистического блока и количественного исследования; была показана направленность происходящего и приведены данные опросов, позволяющие трактовать ее характер и прогнозировать вероятное развитие [Константиновский, Попова 2020].

В представленной статье интерпретируются результаты блока качественного исследования: показаны новые характерные черты формирования образовательных, профессиональных, в целом жизненных траекторий. Представляется, что эти и полученные ранее в проекте данные являются индикаторами существенных перемен, которые происходят не только в отношении к образованию и его статусе в общественном мнении, но и свидетельствуют о значительных трансформациях социального поведения современников в более широком плане.

\footnotetext{
1 Константиновский Д.Л., Попова Е.С. (2016) Отношение молодежи к образованию в современной России // Общественные науки и современность. № 1. С. 5-19; Константиновский Д.Л., Попова Е.С. (2018) Российское среднее профессиональное образование: востребованность и специфика выбора // Социологические исследования. № 3. C. 34-44. DOI: 10.7868/S0132162518030030; Константиновский Д.Л., Попова Е.С. (2020) Среднее vs высшеe // Мир России. Т. 29. № 2. С. 6-26. DOI: 10.17323/1811-038X-2020-29-2-6-26
} 


\section{Перемены и интерпретации}

Фиксируемые изменения вызвали необходимость переосмысления привычных представлений. Варианты ответов на вопрос «почему так происходит?» в социологических исследованиях определялись теоретико-методологическими подходами, концептуальными рамками и исследовательской оптикой.

Значительные перемены, произошедшие в стране, переопределили жизненные карьеры прежде всего молодых людей. Новые черты в освоении ими социальных ролей и достижении профессиональных статусов стали видны в их социальном поведении в сферах образования и труда. Исследования возникших трансформаций сфокусировались главным образом на молодежи, поскольку она, как правило, оказывается наиболее уязвимой группой в период значимых экономических и социальных перемен, но при этом - группой, которая «чаще, чем любая иная, готова преодолевать прекарное состояние», инвестируя в образование, расширяя социальные практики и ресурсы адаптации [Касаткина, Шумкова 2020, с. 214]; такой выбор объекта позволял выявить наиболее существенные характеристики происходящего. Вместе с тем это не означает, что такие характеристики свойственны только молодежи: они присущи (будучи, конечно, не единообразно представлены) и школьнику, выбирающему будущее, и его старшему современнику, задумывающемуся о своих перспективах или вынужденному реагировать на неожиданные либо ожидаемые вызовы, поскольку и тот и другой находятся, по существу, в сходных ситуациях. В этом плане было бы неверно как противопоставлять молодежь более старшим поколениям, так и предполагать, что новые черты ориентаций и социального поведения в сфере образования свойственны всем, независимо от возрастного или иного статуса.

Направление, анализирующее детерминанты выбора будущей образовательной траектории, наиболее широко представлено в отечественной социологии. Традиционно рассматриваются первичные и вторичные эффекты социального происхождения, территориальное неравенство, а также влияние успеваемости и результатов ЕГЭ. В исследованиях показано, что решение девятиклассников о продолжении обучения в старших классах школы или переходе в СПО значимо связано с социально-экономическими характеристиками семьи [Бессуднов, Малик 2016], при этом оно не зависит от уровня успеваемости. Также анализ свидетельствует, что и после окончания средней школы успеваемость не влияет на выбор обучения в СПО (исключение составляют только отличники) [Богданов, Малик 2020, с. 407]. Роль социального происхождения на каждом этапе образовательной траектории, как показывает международный контекст, является одной из отличительных черт образовательных переходов в России [Косякова $u$ др. 2016, с. 92]. Социальное неравенство не только не редуцируется, но и продолжает закрепляться в социальном поведении акторов на протяжении их образовательной траектории. Значимости факторов социально-культурной и экономической стратификации не уступает степень выраженности территориального барьера [Константиновский и дp. 2006]. Региональные особенности рынка труда, образовательной инфраструктуры, реальных доходов населения, стоимости переезда для обучения в вузе в областном центре или столице, как и стоимость жизни в них, а также наличие СПО рядом с местом проживания вынуждают оценивать целесообраз- 
ность окончания средней школы и получения среднего профессионального либо высшего образования. Введение ЕГЭ несколько способствовало образовательной мобильности выпускников школ, однако преимущественно среди выходцев из семей с высоким социально-экономическим статусом [Богданов, Малик 2020, с. 400]. Институциональный анализ позволяет уяснить, что российская система образования характеризуется средним уровнем формальной дифференциации и относительно высоким (при этом малоизученным) уровнем неформальной дифференциации, что создает дополнительные возможности для воспроизводства и усиления социального неравенства [Косякова и др. 2016, с. 78].

Экспансия профессионального образования на протяжении второй половины XX в. [Johnson, Elder 2002] и наблюдаемая в то же время его инфляция [Karabel 1972], риторика «рынка образовательных услуг», доступность получения «корочек» свидетельствуют об определенном кризисе, изменении социальной ценности образования, представлении о нем как об инструменте для мобильности отдельных индивидов, а не для эффективного приращения человеческого капитала [Касаткина, Шумкова 2020, с. 206-207]. К тому же сигналы с рынка труда предупреждают о затруднительности положения значительной части выпускников вузов, осознавших, что наличие диплома о высшем образовании не гарантирует, как прежде, стабильной занятости, не защищает от прекаризации, не минимизирует риски длительной безработицы [Петухов 2020, с. 126; Черныш 2019; Гимпельсон 2019].

Эти и другие перемены оказались весьма существенными, и реакция на них последовала неизбежно. Она ярко проявилась у молодежи, поскольку для нее задача выбора дальнейшего пути наиболее актуализирована. В трансформации смыслов ее социального поведения и вслед за ними в образовательных траекториях, профессиональных карьерах, шире - жизненных стратегиях как ответа на неопределенность, текучесть социального мира [Bauman 2005] - проявляется потенциал ее реактивности. Сказываются характерные для новых поколений черты: стремление к гибкости и мобильности, «нетерпеливость» в поиске возможностей для быстрого успеха (и материального, и профессионального) [Радаев 2018, с. 20], способность противостоять (либо обойти) действующие институты и правила игры [Темницкий 2020, с. 186], а также иное, чем у предыдущих поколений, отношение к труду и снижение значения заработка, социального статуса [Зубок, Чупров 2020, с. 20-21]. Жизненные траектории больше не вмещаются в традиционную модель, становясь сложно предсказуемыми и высоко зависимыми от личного выбора [Ядова 2017, с. 92; Радаев 2020, с. 32]. Судя по всему, произошли кардинальные изменения представлений о долгосрочных целях, стратегии планируются посредством поэтапного формирования будущего [Резник, Смирнов 2002; Абульханова-Славская 1991, с. 67]. Выбирается не одна профессия навсегда, а отдается предпочтение качеству жизни и рациональному распоряжению временем. Поскольку долгосрочное планирование в текущих условиях затруднительно, выигрывают ориентирующиеся на краткосрочную перспективу в преодолении того, что можно назвать «забегом с препятствиями» (имеются в виду барьеры в образовании и при выходе на рынок труда).

Необходимость ответа на возникшие вызовы вынуждает исследователей находить новые данные и искать концепты, соответствующие новой реальности: «планирование без форсайта» [Зубок, Чупров 2020, с. 18], модель «социального серфинга» [Ильин 2019], «калейдоскопный» тип формирования карьеры [Ядова 2017, с. 103], «дисперсивная» жизненная модель, проявляющаяся 
в параллельном получении нескольких профессий и фрагментарно-кумулятивном накоплении навыков и опыта [Касаткина, Шумкова 2020, с. 215]. Предлагаемое исследование вводит в оборот новые данные, полученные качественными методами, и расширяет возможности интерпретации, поскольку включает в рассмотрение биографии респондентов разных возрастов, которые ретроспективно оценивают свой опыт выбора.

\section{Качественное исследование}

\section{Методика и информачионная база}

Информационной базой качественного исследования являются материалы проекта «Горизонтальная профессиональная мобильность и образовательные стратегии населения в контексте технологического развития РФ (социологический анализ)» ${ }^{2}$. Дизайн выборки обусловила задача разработки статистических данных в разрезе региональной специфики - Москва и Московская область, Республика Татарстан и Красноярский край как регионы, демонстрирующие высокие показатели по индексу инновационной деятельности (ИИД) и индексу готовности к будущему (ИГБ), а также показывающие высокую долю участвующих в программах переподготовки.

Были проведены глубинные интервью по широкому кругу вопросов, связанных с мотивацией, перспективами смены профессии и получения соответствующего этому образования. Интервью проводились со слушателями и выпускниками программ профессиональной переподготовки $(\mathrm{N}=56)$, треть которых - работники до 30 лет включительно, восьмая часть - старше 45 лет. Поиск респондентов осуществлялся методом снежного кома через центры занятости и профессиональной переподготовки, а также через социальные сети по хештегу «\#сменапрофессии». Обращение в республиканские и краевые центры занятости позволило охватить исследованием респондентов из сельской местности, малых городов и поселков городского типа. В соответствии с целями анализа были отобраны 36 интервью, в которых содержится значимый для интерпретации материал о выборе образовательной, профессиональной и жизненной карьеры; они проводились с молодыми и принадлежащими к более старшим поколениям респондентами (таблища 1).

Следуя правилу разграничения логики исследования и логики кодирования, при анализе материалов интервью применялась система двойного кодирования. Первичный анализ материалов строился от исследовательских вопросов к тексту (в соответствии со схемой, предложенной 3. Ламнеком [Qualitative Text Analysis 2013, p. 34]), анализу возникающих категорий и/или реинтерпретации существующих в теоретико-методологической части концептов. Респонденты, осуществляющие смену профессии и расширяющие спектр образовательных усилий, в частности, путем прохождения программ профессиональной переподготовки, являются немногочисленной и специфической группой, однако длина, наполненность и особенности их образовательных карьер позволили получить содержательные нарративы, которые легли в основу настоящего исследования.

2 Проект РНФ №17-78-10204, 2017-2019 гг. 
Таблица 1. Распределение респондентов по возрасту и образованию, чел.

\begin{tabular}{|c|c|c|}
\hline Возраст & СПО / СПО + BО & ВО \\
\hline $20-29$ лет & 2 & 8 \\
\hline $30-39$ лет & 7 & 12 \\
\hline $40-49$ лет & 2 & 3 \\
\hline $50+$ & 2 & 0 \\
\hline Итого & $\mathbf{1 3}$ & $\mathbf{2 3}$ \\
\hline
\end{tabular}

\section{Результатьл}

Наиболее ярким свойством, отличающим биографии наших респондентов, оказалась нелинейность траекторий ${ }^{3}$ - образовательных, профессиональных, жизненных. Канули в прошлое времена, когда человек получал определенное профессиональное образование или приходил на рынок труда, где овладевал нужными навыками, потом совершенствовался именно в этой профессии, получал дополнительное образование, соответствующее ее профилю, порой заканчивая карьеру на том же предприятии или организации, где и начинал свой трудовой путь. Это было вполне линейное движение, магистраль. Перемены профессии бывали, перемены места работы - тем более, но это не было правилом, как и периоды более или менее длительного поиска работы. Однако в настоящее время ситуация изменилась, и возврат к прошлому состоянию уже не представляется вероятным (во всяком случае, сегодня).

Респонденты, избравшие траектории, связанные со средним профессиональным образованием, отмечают его безусловно положительные стороны - практикоориентированный характер, ценность приобретаемых конкретных навыков и знаний. Прикладной характер специальности, непродолжительный период обучения и относительная легкость последующего трудоустройства составляют ядро мотивации тех, кто предпочел среднее профессиональное образование. При этом выбор отнюдь не оценивается как компромиссный и полностью уступающий варианту высшего образования, но представляется как конкурентный по отношению к нему.

«Вот я бы и не сказал, что наше профобразование сейчас уступает вузовскому. $<\ldots>$ Если уже на специалиста даже переучиваться. Меня же сразу в прикладном плане обучили» (№ 66, муж., 35 лет, Красноярск).

Трудоустройству респондентов в дальнейшем способствовал высокий спрос на рынке труда на некоторые рабочие специальности в регионах, где проводились интервью. Оно облегчалось, если у респондента имелись профессиональный опыт

3 Под траекторией в образовании и профессии понимается последовательность определенных решений и шагов по их реализации. 
и практические навыки; и напротив, отсутствие опыта работы затрудняло трудоустройство. В любом случае магистральный вариант траектории не являлся правилом, скорее, наоборот.

«Рынок-то хорочий, предложений много, в основном требуются спещуиалисты с опытом. Вот и получается, что сначала надо идти работать за 15 тысяч, хотя бы на полгода, а потом уже смотреть дальше» (№ 66, муж., 35 лет, Красноярск).

Особенности траектории «среднее общее + СПО» могут быть связаны (для определенных слоев учащихся) с более поздним осознанием труднодоступности высшего образования либо сопряжены со стратегией избегания неудачи при поступлении в вуз и минимизации рисков. Оценивая ретроспективно свой выбор после 11-го класса начать получение профессионального образования в СПО с прицелом на вуз, наши респонденты подчеркивают, что в дальнейшем при построении нелинейной траектории им помогало тесное переплетение образовательных и профессиональных карьер: кто-то начал работать еще в школьные годы и выбирал специальность СПО, чтобы подтвердить и повысить уже освоенные квалификации; большинство трудоустраивались по полученной профессии либо во время производственной практики в СПО, либо сразу после окончания; а получение высшего образования оказывалось для них более доступным по мере того, как они становились на ноги.

«Тут-то главное - устроиться, а потом уже [вуз] заочно можно закончить, зарабатывая свои деньги, как-то уже откладьвая <..> можно пойти на заочку, $<\ldots>$ а ведь все остальное время у тебя уже будут свои собственные деньги» (№ 68, жен., 37 лет, Красноярск).

Для респондентов, избравших высшее образование сразу после окончания среднего общего, характерна рефлексия относительно случайности этого решения, неуверенности в его правильности, а нередко и последующего разочарования в его реальной необходимости.

«Нужно было еще одну корочку получить, родители так в детстве сказали. Ну а потом действительно важно: вот ты проходишь собеседование, и тебя начинают спрашивать: “А где Bы учились?”. Начинаешь рассказывать, где, и тебя хоть как-то иченят. Но это только когда ты устраиваешься на работу, а потом об этом забывают сразу же; никто потом и не помнит» (№ 1, жен., 30 лет, Москва).

Единодушие респондентов, очень разных по образовательному, профессиональному опыту и ресурсному капиталу, равно как и по возрасту, возвращает нас к известным (и высказанным в прежних публикациях) сомнениям относительно 
готовности старшеклассников к принятию решения о профессиональном и образовательном будущем, а также соответствия их уровня социализации на этапе окончания школы - степени важности такого решения.

\begin{abstract}
«Я абсолютно точно сейчас понимаю: не надо было бежать после 11-го класса сразу поступать, я бы год поработала, подумала бы, чего я вообще хочу, прислушивалась бы к себе, пообщалась бы с людьми. В России у девочек есть такая возможность. И почему-то мне об этом никто не сказал, а мне это в голову не пришло тогда. Вот это все какая-то спешка, что надо немедленно, когда я просто не спала две ночи в неделю просто потому, что у меня были репетиторы, и я не успевала. И надо было бежать, бежать, бежать, лишь бы поступить, а если не поступишь, то расстрел. Если бы в тот момент я понимала, что это не расстрел, мне не нужно идти в армию, что я могу просто спокойно посуществовать и просто подумать, что я хочу дальше делать... Может, походить на какие-то курсы, тест на профориентацию сдать хотя бы. Ну хоть что-нибудь, чтобы был более осознанный выбор, вот это я точно бы сделала» (№ 28, жен., 32 года, Москва).
\end{abstract}

При часто встречающихся сомнениях относительно образовательного выбора мотивация и ценность получения первого высшего образования нередко сводятся к его сигнальной функции и в какой-то мере декларативному характеру.

«Высшее образование - это как клеймо, которое обязательно должно стоять. Непо-
нятно зачем, но должно» (№ 3, жен., 45 лет, Москва).

Немаловажным фактором, определяющим траекторию, стал ЕГЭ. Производимая им технократическая предопределенность дальнейшего жизненного пути школьника является более ранним воздействием на биографию и обладает более обязывающим и длительным эффектом, чем было обязательное распределение выпускников профессионального образования. Этот необходимый инструмент для функционирования современной системы образования стал играть иную ведущую роль - в выборе образовательной траектории, диктуя, в зависимости от полученных школьником баллов, какое образование он может получить после окончания школы.

«Ну, на бакалавриат поступал, куда баллов хватило, как и больиинство сейчас. Когда предметы выбирал для ЕГЭ, так вообще пальием в небо ткнул. < .. > Куда попал, туда попал» (№ 58, муж., 23 года, Красноярск).

Трудоустройству по получаемой профессии во время обучения в вузе, как и в СПО, часто препятствуют отсутствие опыта в ней, недостаточность знаний и практических навыков, в то время как мотивация и необходимость как мож- 
но раньше выйти на рынок труда актуальны как по материальным причинам, так и вследствие ускоряющихся темпов изменений в экономике. Впоследствии, по окончании вуза, трудоустройство по приобретенной профессии также может оказаться затруднено, и нелинейность становится непременным свойством траектории. Работая не по специальности, обладатели вузовского диплома чаще всего объясняют это невозможностью найти работу, соответствующую профилю обучения, либо получить ее, не имея минимального опыта, а нередко и утратой интереса к профессии или разочарованием в характере предложенной деятельности.

«Нежелание работать по специальности? То есть я учусь, а мне не нравится. Я же хотел изначально пойти в фармкомпанию. Но разносить ручки с листочками мне не хотелось, даже несмотря на то, что машину дают, и зарплата хорошая. Мне этого не хотелось» (№ 4, муж., 30 лет, Москва).

Многосоставные траектории (такие, как «основное общее или среднее общее + рынок труда + СПО», «СПО + рынок труда + вуз») наиболее уязвимы при реализации образовательной стратегии не только из-за множества переходов, но и по причине длительности временного горизонта их реализации [Hillmert, $J a c o b$ 2003, p. 327]. Однако у них есть весомые преимущества. Для респондентов, избравших «длинные» траектории, в наиболее часто встретившихся случаях ни одна из их составляющих не становилась тупиком, разносторонний профессиональный опыт позволял уточнить горизонт дальнейших возможных образовательных усилий и скорректировать образовательную стратегию. Успешности тех, кто отдал предпочтение такому варианту, способствовали их быстрая адаптируемость к изменениям рынка труда, использование ресурсов первого и последующего профессионального образования.

\footnotetext{
"А потом два года экономического техникума, вот и работал. На высшее пошел, мне нравилось: и надо было, и самому интересно. Я вообще в то время еще после техникума мог сразу пойти на 3-й курс экономический, но решил, что мне нужна инженерная специальность. И вот с 1-го курса отучился. Да и, вообще-то, что я работал в этой сфере, мне ведь и учиться было легче. < ... Я Я заочно бесплатно учился, сессия 2 раза в год. < .. > Две недели читали лекции, неделя сессии. На работе отпуск давали второй. Работодатель способствовал, второй оплачиваемый отпуск давал, у нас директор еще той, советской закалки: “Конечно, конечно! Давайте, давайте, учитесь! Что вы еще?? Молодые парни!”» (№ 60, муж., 35 лет, Красноярск).
}

Нелинейный характер траекторий оказался возможен благодаря способности респондентов гибко реагировать на изменения ситуации, подвергать анализу и пересматривать свой опыт, и исходя из этого заново формировать свой дальнейший профессиональный путь в зависимости от текущих обстоятельств, возникающих, прежде всего, на динамичном рынке труда. Респонденты, опрошенные в данном исследовании, могут быть охарактеризованы как «передовой отряд» тех, кто уже в значительной 
мере затронут переменами в нашей реальности (слово «затронут» употреблено нами намеренно для того, чтобы читатель возразил и сам определил суть происходящего).

Конечно, руководствовались респонденты не только переменами на рынке труда, присутствует и влияние семьи, ближайшего окружения, и предшествующего опыта, включающего полученный в период обучения, - это сплав многих факторов, сформировавших устремления.

Судя по всему, пора окончательно расстаться с методологией, основанной на положении «переход от образования к труду» (кстати, разве учеба - не труд?). Она была верна для прошлого устройства общества, хорошо послужила исследовательским целям и задачам. Теперь, когда образовательная и профессиональная траектории слились в нечто целое, обучение и работа по профессии происходят одновременно, чередуются между собой и с периодами безработицы, не разделяются четко, а зачастую сливаются в один процесс. В этой ситуации нужно иное определение того, что очевидно в социальном поведении молодежи и не только молодежи, и, следовательно, иными будут основания для анализа и теоретикометодологические подходы.

Определение наблюдаемого в новой реальности логично поискать не в привычных формулировках, настигающих нас из прошлого опыта, а в понятиях, бытующих именно в этой реальности. Нелинейность, порой перемены, которые могут показаться внезапными, продвижение и, возможно, возвращение к исходному с последующим новым движением вперед, неожиданные (в действительности имеющие объяснения) повороты чрезвычайно похожи на то, что имеет определенное название - «квест».

Главное для этого жанра - необходимость на каждом этапе (в нашем случае образовательной и профессиональной карьеры) исследовать открывающиеся необходимости и возможности, пытаться ответить на первые и использовать вторые, и двигаться, двигаться к цели. Не очевидно ли сходство с траекториями наших респондентов? При этом обратим внимание на следующую важную особенность их социального поведения: они реагируют на необходимости, которые возникают, но руководствуются чаще и в большей степени именно открывающимися возможностями; не вынужденность в таких случаях заставляет их действовать, а обнаружение или создание новых вариантов траектории. Метафорой «квест» определяется тенденция, дающая место выбору индивида и вероятности событий биографии (вероятности, где на самом деле шанс определяется не рулеткой, а решением индивида), где усилия побеждают барьеры и предопределенности, - тенденция, которая (доверимся нашим респондентам) утверждается.

Другой важной характеристикой биографий наших респондентов является их отношение к социальной мобильности. Социальные перемены привели к изменению как объективной, так и субъективной мобильности [Семенова и дp. 2019, с. 15-72], и понимание мобильности индивидами стало иным, сделалось другим и отношение к возможностям для нее. Респондентка, по собственной инициативе перешедшая на работу, которая может оцениваться как менее престижная, так объясняет свое решение:

«Хотя мой папа говорит, что это дауниифтинг, ая вообще так не считаю. Та ответственность, с которой мне приходится здесь сталкиваться, многим моим офисным 
коллегам вообще не снилась. Люди в офисе не могут решать какие-то маленькие вопросы по бизнесу, боятся брать ответственность за решение и занимаются вечной пересылкой писем. В этом нет эффективности или производительности труда. Я чувствую, что в офисе я просто тупею от этой пересылки писем. Здесь же настоящая жизнь и люди, которые горят своим делом» (№ 5, жен., 31 год, Москва).

Необходимости и возможности, как следует из материалов интервью, складывались для отдельно взятого респондента по-своему, создавая специфику личной ситуации, которую каждый из них при интервьюировании невольно подвергал анализу. Были респонденты вполне благополучные, располагающие ресурсами и стремящиеся к восходящей мобильности, к реализации своих предпочтений; другие были обеспокоены невысокой оплатой труда, монотонной работой, испытывали последствия эмоционального и профессионального выгорания; у третьих, казалось бы, не существовало особых причин для тревог, но они искали новое место в жизни; были и оказавшиеся в группе риска, растерянные от происходящего с ними.

В каждой из этих категорий встречались два вида реакции на специфику личной ситуации: индивиды выстраивали либо стратегию стабильности, либо стратегию мобильности ${ }^{4}$. Первая была ориентирована на сохранение и закрепление текущего рабочего места и статуса, обычно с одновременным поиском дополнительного (официального или неофициального) заработка. Другая предполагала использование возможностей (прежде всего образования) как трамплина для продвижения. Именно собственное образование респонденты подвергали своеобразному экзамену, оценивая свое положение на рынке труда и сравнивая свой текущий статус с желаемым. Оно становилось главным ресурсом, анализируемым респондентами при обсуждении возможности продвижения, которое могло осуществляться на том же предприятии, где респондент работает (тем успешнее, чем эффективнее окажется поддержка руководства), или потребовать смены места работы.

При выборе респондентом той или иной стратегии проявляется важнейший фактор, с некоторой долей вероятности определяющий модель того или иного дальнейшего социального поведения, - проактивность. Выигрывают инициативные респонденты, осознанно выбирающие свою реакцию на новые необходимости и возможности. При этом они реалистично и нередко, пожалуй, слишком критически дают оценки своему настоящему, определяя цели на будущее. В итоге они оказываются в состоянии контролировать формирование дальнейшей образовательной и профессиональной (и в целом жизненной) траектории.

\footnotetext{
«В связи с тем, что я много чего уже поменял в жизни, это убрало у меня страх к изменениям: ну будем подстраиваться, эволюции ведь на то и эволюичя. < .. > Да, да. Появляются инициатива, проактивность. То, что постоянно нужно развиваться, значит постоянно нужно учиться. За тебя никто ничего делать не будет. Тем более сейчас, кто бы что ни говорил, у среднестатистического жителя России, если мы говорим про Россию, есть все возможности для самостоятельного образования:
}

4 В данном контексте стратегия понимается как долгосрочный план, позволяющий из текущего состояния перейти в целевое [Константиновский и др. 2015, с. 100]. 
тыл можешь изучить, что хочешь. По факту. Не надо мне говорить о бедности. Много всего бесплатного; можно, простите, и пиратское найти. Все зависит от желания, потому что сейчас с доступностью Интернета ну нет, нет ограничений. Я постараюсь сказать, надеюсь это и будет правильно: нет ограничения в возможностях, есть ограничения в средствах, в здоровье, но в возможностях ограничений нет. Много примеров, которые я вижу вокруг себя и в мире, они только укрепляют мою веру в это, что именно в возможностях ограничений нет, ограничения могут быть другого толка. А так ты можешь научиться, чему хочешь, и делать, что хочешь» (№ 25, муж., 30 лет, Москва).

Респонденты, участвовавшие в исследовании, не являются специалистами по социальной структуре, но многие вполне успешно ориентируются в ней, определяя свое место в современном российском обществе и прогнозируя собственное будущее. Им видны сегодняшняя многомерность социальной структуры [Черныши, Епихина 2018], отличие ее от прежних состояний и роль образования в том, какую позицию в социуме сами они занимают и могут занять в будущем при выполнении определенных условий. Об этом свидетельствуют их высказывания по поводу прошлых событий собственной биографии, предпринятых некогда шагах (конечно, они рационализируют, когда реконструируют прошлое, но в данном случае это, скорее, помогает сделать верные оценки) и тех действий, которые ими намечены.

Еще одна существенная характеристика биографий наших респондентов - присутствие обстоятельств неравенства в доступности образования и конструктивное осознание их. Тематика неравенства неизменно присутствовала в интервью, она возникала по разным поводам. Текущая ситуация с образовательным неравенством в России во многих смыслах напоминает русскую матрешку: не только тем, что под одним социальным явлением и теоретическим концептом, поясняющим его, кроются многообразие и вариативность содержания и форм, но и тем, что при потенциальном и декларируемом равенстве шансов на реализацию образовательных и профессиональных траекторий наблюдаемое неравенство приобрело привычные черты вполне обычного, если не сказать традиционного, положения дел. В частности, подтверждалось, что образовательная траектория «основное общее + СПО», рассматриваемая в практике социологических исследований как «стратегия подстраховки» [Hillmert, Jacob 2003, p. 320], чаще распространена среди учащихся из малоресурсных семей. Значение инвариативных барьеров за последнее десятилетие усилилось, это подчеркивается респондентами при сравнении социально-экономического контекста собственного образовательного выбора и тех решений, которые принимаются родителями относительно образовательных траекторий детей.

\footnotetext{
«Чтобы идти в высшее, надо было заканчивать 11 классов. А я говорю, что мы такую сумму просто не потянем. Вот как платить-то? <..> $B$ инстиmутах этих от 120 тысяч - это же минимальная вообще изена. А куда мы хотели, так там вообще 160 тысяч в год, а где-то и все 180, ну такую сумму нам просто не потянуть. Поэтому я и говорю: “Давай уйдем после 9-го, и меньше проблем будет”. А этот ЕГЭ! Mbl из-за него поседели обе» (№ 68, жен., 37 лет, Красноярск).
} 
Респонденты представляют массовые слои населения, и это не дети высокопоставленных администраторов, влиятельных специалистов или состоятельных бизнесменов. Их собственные ресурсы ограничены той позицией, которую они в данный момент занимают, и поддержка родителей невелика. Мы убедились, что патерналистских надежд у них нет: это новое поколение, сформировавшееся уже вне влияния установок советского времени. Они рассчитывают на себя, на свои усилия и возлагают надежды на образование. Они понимают, что именно там лежит путь к желаемому статусу. В то же время им ясно, что образование не является универсальным пропуском в будущее, где их ждали бы, как когда-то, гарантированное получение рабочего места и соответствующее социальное вознаграждение. Необходимое для респондентов образование должно обладать качествами, которые понадобятся в проектируемом завтра, к тому же обладание им должно сочетаться с другими обстоятельствами, не всегда полностью зависящими от индивида. Является ли сегодня образование мощным социальным лифтом? Но респонденты и не ожидают, что образование, которое они могут надеяться получить, вознесет их к вершинам социума. Их надежды скромны, но жизненно важны для них. Одним этот путь обещает дать исполнение мечты и реализацию природного дара, другим - такую работу, которая даст надежное место в жизни, третьим обрести опору, когда для них все стало шатким и неопределенным.

Решимость наших респондентов покинуть группы «новых меньшинств»не имеющих нужного образования, низкооплачиваемых - понуждает их к активности. Они реально действуют, не ограничиваясь намерениями, используя возможности сферы образования, обходя ее несовершенства и преодолевая формальные и неформальные препятствия. Текущая профессиональная позиция чаще воспринимается как исходная, пройденный образовательный путь не оценивается как тупиковый и, что чрезвычайно важно, в самом деле не является таковым в отечественной системе образования, которая предоставляет необходимые возможности для дальнейшего выбора. Этот выбор - не просто получение высшего или дополнительного образования, а такого, которое дает возможности для самореализации и в то же время адекватно динамике рынка труда.

\section{Заключение}

Вполне определенный характер изменений в социальном поведении, проявляющихся в образовательных ориентациях и реальном построении образовательных и профессиональных карьер, не может не убеждать, что эти явления могут повлечь за собой перемены не только в сфере образования, но и иметь последствия для формирования человеческого капитала. Полученные в проекте результаты исследования причин и характеристик происходящего количественными и качественными социологическими методами выявляют его значимость.

Анализ показывает, что наиболее отличительная черта, характерный признак современных образовательных, профессиональных, жизненных траекторий - их нелинейность. В этом наши результаты вполне согласуются с выводами, полученными коллегами с применением иных теоретико-методологических подходов. Предлагаемая нами метафора «квест образовательного пути» (и не только образовательного), 
на наш взгляд, позволяет подступиться ближе к пониманию смыслов динамики формирования образовательной и профессиональной карьеры, значения цели и мотивов в ее реализации, субъективных координат социальной мобильности.

Помимо типичных образовательных траекторий, которые традиционно представляются массовыми, также показано поле иных образовательных ходов. Они становятся возможными благодаря относительной открытости отечественной системы профессионального образования - ее несомненно положительной черты, и обуславливаются тем, что вызывает и обеспечивает новый характер траекторий: гибкостью реакций на изменения, способностью корректировать образовательный и профессиональный путь в зависимости от текущих обстоятельств динамичного рынка труда. В формировании как мотивации, так и в целом социального поведения респондентов видна определяющая роль проактивности, в значительной степени детерминированная ростом влияния социокультурных факторов. Развитие Интернета, социальных сетей (вообще расширение источников информации) способствуют тому, что ускоряются, интенсифицируются становление самосознания индивидов, освоение и осознание ими новых обстоятельств, происходящих изменений. Возникает новый эффект - «коллективное мышление»: каждый принимающий решения относительно себя находится в широком круге социума и оказывается реципиентом влияний, исходящих из самых разных источников. Неясно, все ли эти влияния благие, но расширение возможностей безусловно увеличивает потенциал для ориентирования в текущей ситуации, преодоления препятствий и достижения желаемого результата. Также мы наблюдаем, как при рождении решений о будущем осмысление социального неравенства в доступе к профессиональному образованию создает новые возможности для сокращения периода реализации профессиональной траектории и повышения ее эффективности.

Возможно, отмечаемые в исследованиях неопределенность, размытость образовательных решений тех, кто избирает высшее образование (зачастую без конкретного выбора специальности или даже направления обучения), связаны не только с неготовностью к проектированию своего будущего, но и с широтой спектра потенциальных образовательных возможностей и с высотой инвариативных, зачастую латентных барьеров. И то и другое может становиться препятствием для более успешного дальнего планирования, а потому риск неверных решений или разочарования в выборе для этой группы респондентов выше. В противовес этому образовательные возможности СПО (их предложение) конкретны, их диапазон более определенен и теснее связан с региональной спецификой рынка труда, а потому выбор может быть целенаправленнее, образовательная стратегия короче по времени и прозрачнее; как следствие, возникает вероятность того, что адекватность образовательных решений окажется выше (хотя эффективность достигается чаще в горизонте краткосрочного планирования, а затем, в общем случае, уступает той, что возможна после длинной дистанции получения высшего образования ${ }^{5}$. Интерпретация высказываний наших респондентов позволяет заключить, что на первый взгляд невыгодные, кажущиеся иррациональными стратегии предпочтения среднего профессионального образования в логике социального поведения могут свидетельствовать, напротив, о рациональности, практичности.

\footnotetext{
5 «По-прежнему сохраняется высокая премия за высшее и скромная, но все же ощутимая премия за среднее профессиональное образование. Получение вузовского диплома способствует повышению заработков примерно вдвое. Обучение в ссузах не выглядит экономически бессмысленным, обеспечивая прибавку к заработкам порядка 15-25\%» [Капелюшников 2021, с. 42].
} 
Вынужденность в принятии жизненных решений не исчезла, она не может не присутствовать во многих из них; гарантий безоблачных перспектив не дано. Однако преодолению препятствий способствуют трезвая оценка вероятности позитивного исхода и возможностей продвижения, отказ от патерналистских надежд и реалистический выбор тактики мобильности либо стабильности. Притом достигнутый или планируемый при формировании траектории уровень образования и позиция в профессионально-квалификационной структуре общества воспринимаются не как конечные, но как исходные, как очередные стартовые на каждом этапе траектории; они не привязывают индивида к себе, а предоставляют ему необходимые возможности для дальнейшего выбора в сферах образования и труда. Остается открыть для себя эти возможности (что наши респонденты, как правило, делают весьма успешно) и осваивать их, осмысливая свой опыт. Анализ в качественной логике исследования показал, что речь идет о последовательном накоплении трудового опыта и получении на каждом этапе адекватного образования, соответствующего профессиональной ситуации.

Несомненно, отмеченное в образовательных траекториях является как следствием, так и отражением демографических, социально-экономических, когнитивных и иных процессов и несет в себе специфические российские черты. Происходящее не противоречит подтверждаемой во многих публикациях массовизации высшего образования, но ставит перед исследователями новые вопросы. Выявленные тенденции социального поведения в сферах образования и труда - эпизод или нечто весьма устойчивое? Изменения в образовательных, профессиональных (выбор вида образования, профессии) и жизненных траекториях вследствие таких воздействий, как пандемия коронавируса, проявляются временно или способны задать новый характер происходящему в целом? Ускоряются ли сложившиеся тренды или, оказавшись в своеобразных точках перелома, современники лишь действуют ситуативно, исходя из личных представлений и имеющихся сегодня возможностей [Радаев 2018]? Что мы наблюдаем сегодня: девальвацию профессионального образования, кризис achieving [McClelland 2010] и credential societies [Collins 2019], расцвет deschooling society [Illich 2000]? Судя по всему, можно ожидать, что возникающие вопросы определят новый мейнстрим в социологии образования.

\section{Список источников}

Абульханова-Славская К.А. (1991) Стратегия жизни. М.: Мысль.

Бессуднов А.Р., Малик В.М. (2016) Социально-экономическое и гендерное неравенство при выборе образовательной траектории после окончания 9-го класса средней школы // Вопросы образования. № 1. С. 135-167.

Богданов М.Б., Малик В.М. (2020) Как сочетаются социальное, территориальное и гендерное неравенства в образовательных траекториях молодежи России? // Мониторинг общественного мнения: экономические и социальные перемены. № 3(157). C. 391-421. DOI: 10.14515/monitoring.2020.3.1603

Гимпельсон В.Е. (2019) Возраст и заработная плата: стилизованные факты и российские особенности // Экономический журнал Высшей школы экономики. № 2. С. 185-237. DOI: $10.17323 / 1813-8691-2019-23-2-185-237$ 
Зубок Ю.А., Чупров В.И. (2020) Жизненные стратегии молодежи: реализация ожиданий и социальные настроения // Мониторинг общественного мнения: экономические и социальные перемены. № 3(157). С. 13-41. DOI: 10.14515/monitoring.2020.3.1602

Ильин В.И. (2019) Социальный серфинг как модель молодежного образа жизни // Мониторинг общественного мнения: экономические и социальные перемены. №1(149). C. 28-48. DOI: 10.14515/monitoring.2019.1.02

Капелюшников Р.И. (2021) Отдача от образования в России: ниже некуда? Препринт WP3/2021/03. М.: ВШЭ.

Касаткина Н.П., Шумкова Н.В. (2020) От самообразования к самозанятости: непарадный вход молодежи на рынок труда // Мониторинг общественного мнения: экономические и социальные перемены. № 3(157). C. 201-223. DOI: 10.14515/monitoring.2020.3.1600

Константиновский Д.Л., Абрамова М.А., Вознесенская Е.Д., Гончарова Г.С., Костюк В.Г., Попова Е.С., Чередниченко Г.А. (2015) Новые смыслы в образовательных стратегиях молодежи: 50 лет исследования. Монография. М.: ЦСП и М.

Константиновский Д.Л., Вахштайн В.С., Куракин Д.Ю., Рощина Я.М. (2006) Доступность качественного общего образования: возможности и ограничения. М.: Логос.

Константиновский Д.Л., Вознесенская Е.Д., Чередниченко Г.А. (2013) Рабочая молодежь сегодня: образование, профессия, социальное самочувствие // Социологическая наука и социальная практика. Т. 0. № 2. С. 21-38.

Константиновский Д.Л., Попова Е.С. (2020) Среднее vs высшее // Мир России. Т. 29. № 2. С. 6-26. DOI: 10.17323/1811-038X-2020-29-2-6-26

Косякова Ю., Ястребов Г.А., Янбарисова Д.М., Куракин Д.Ю. (2016) Воспроизводство социального неравенства в российской образовательной системе // Журнал социологии и социальной антропологии. № 5(19). С. 76-97.

Петухов В.В. (2020) Российская молодежь и ее роль в трансформации общества // Мониторинг общественного мнения: экономические и социальные перемены. № 3 . C. 119-138. DOI: 10.14515/monitoring.2020.3.1621

Радаев В.В. (2018) Миллениалы на фоне предшествующих поколений: эмпирический анализ // Социологические исследования. № 3. C. 15-33. DOI: 10.7868/S0132162518030029

Радаев В.В. (2020) Раскол поколения миллениалов: историческое и эмпирическое обоснование. (Окончание) // Социологический журнал. Т. 26. № 4. С. 31-60. DOI: $10.19181 /$ socjour.2020.26.4.7641

Резник Ю.М., Смирнов Е.А. (2002) Жизненные стратегии личности (опыт комплексного анализа). М.: Институт человека РАН.

Саганенко Г.И., Степанцова А.А., Степанова Е.И. (2015) Профессиональные предпочтения молодежи как показатель общественных перемен // Высшее образование в России. № 2. C. 59-70.

Семенова В.В., Черныш М.Ф., Сушко П.Е. (ред.) (2019) Социальная мобильность в усложняющемся обществе: объективные и субъективные аспекты. Монография. М.: ФНИСЦ РАН.

Темницкий А.Л. (2020) Формирование индивидуальной субъектности в сфере труда у молодых работников современной России // Мониторинг общественного мнения: экономические и социальные перемены. № 3(157). С. 182-200. DOI: $10.14515 /$ monitoring.2020.3.1660

Черныш М.Ф. (2019) Поиск работы по неформальным каналам как фактор социальной дифференциации в молодежной среде // Информационно-аналитический бюллетень. ИНАБ. № 4. Социальная адаптация молодежи на рынке труда. С. 21-38. DOI: $10.19181 /$ inab.2019.4.2

Черныш М.Ф., Епихина Ю.Б. (ред.) (2018) Многомерная социальная мобильность в современной России: монография. М.: Институт социологии ФНИСЦ РАН. DOI: 10.19181/monograph.2019.3

Ядова М.А. (2017) Образовательные и профессиональные стратегии постсоветской молодежи // Россия и современный мир. № 2(95). C. 91-104. DOI: 10.31249/rsm/2017.02.06

Bauman Z. (2005) Liquid Life, Cambridge, UK; Malden, MA: Polity.

Collins R. (2019) The Credential Society: An Historical Sociology of Education and Stratification, New York: Columbia University Press. 
Hillmert S., Jacob M. (2003) Social Inequality in Higher Education: Is Vocational Training a Pathway Leading to or Away from University? // European Sociological Review, vol. 3, no 19, pp. 319-334. DOI: 10.1093/esr/19.3.319

Illich I. (2000) Deschooling Society, London: Marion Boyars.

Johnson M., Elder G. (2002) Educational Pathways and Work Value Trajectories // Sociological Perspectives, vol. 45, no 2, pp. 113-138. DOI: 10.1525/sop.2002.45.2.113

Karabel J. (1972) Community Colleges and Social Stratification // Harvard Educational Review, vol. 42, no 4, pp. 521-562. DOI: $10.17763 /$ haer.42.4.46m282672517k642

McClelland D.C. (2010) The Achieving Society, Martino Publishing: Mansfield Centre.

Qualitative Text Analysis: A Guide to Methods, Practice and Using Software (2013), SAGE Publications Ltd.

\title{
From the Perception of Social Changes towards Social Behavior Change
}

\section{D.L. KONSTANTINOVSKIY*, E.S. POPOVA**}

\begin{abstract}
*David L. Konstantinovskiy - DSc in Sociology, Head of Department of Sociology of Education, Institute of Sociology FCTAS RAS, Moscow, Russian Federation, scan21@mail.ru, https://orcid.org/0000-0003-3316-0644

**Ekaterina S. Popova - PhD in Sociology, Leading Researcher, Institute of Sociology FCTAS RAS, Moscow, Russian Federation, espopova@isras.ru, https://orcid.org/0000-0002-9808-3152

Citation: Konstantinovskiy D.L., Popova E.S. (2022) From the Perception of Social Changes towards Social Behavior Change. Mir Rossii, vol. 31, no 1, pp. 6-24 (in Russian). DOI: $10.17323 / 1811-038 X-2022-31-1-6-24$
\end{abstract}

\begin{abstract}
The article is devoted to the analysis of changes in the educational and professional trajectories of both younger and older generations. The research is based on interviews with respondents of different ages who investigate their life experience retrospectively. Our analysis of these biographies reveals that the educational and professional trajectories are non-linear and depend on respondents' attitudes towards social mobility and inequality in access to professional education. The respondent tended to one of the types of reaction to the specifics of his/her situation: strategy of stability or strategy of mobility, and the model of social behavior was determined by his/her proactivity. The variety and flexibility of the choice of the further path became possible to a large extent due to the relative openness of the Russian system of professional education. To characterize the choice of educational and professional trajectories, we propose the metaphor of "a quest", which emphasizes the need to recognize new circumstances and to act accordingly. The nature of the changes suggests they are not bound to the field of education alone, rather they have important implications for the formation of human capital in general, and define a new mainstream in the sociology of education.
\end{abstract}

Keywords: education, educational trajectories, professional trajectories, vocational education, higher education, labor market, social mobility, inequality

The article was received in June 2021. 


\section{References}

Abul'khanova-Slavskaya K.A. (1991) Strategy of Life, Moscow: Mysl' (in Russian).

Bauman Z. (2005) Liquid Life, Cambridge, UK; Malden, MA: Polity.

Bessudnov A.R., Malik V.M. (2016) Socio-economic and Gender Inequality in Choosing an Educational Trajectory after the End of the 9th Grade of Secondary School. Voprosy obrazovaniya / Educational Studies Moscow, no 1, pp. 135-167 (in Russian).

Bogdanov M.B., Malik V.M. (2020) How Are Social, Territorial and Gender Inequalities Combined in the Educational Trajectories of Russian Youth? Monitoring of Public Opinion: Economic and Social Changes, no 3(157), pp. 391-421 (in Russian). DOI: $10.14515 /$ monitoring.2020.3.1603

Collins R. (2019) The Credential Society: An Historical Sociology of Education and Stratification, New York: Columbia University Press.

Chernysh M.F. (2019) Job Search through Informal Channels as a Factor of Social Differentiation in the Youth Environment. Informational and Analytical Bulletin, no 4. Social Adaptation of Young People in the Labor Market, pp. 21-38 (in Russian). DOI: 10.19181/inab.2019.4.2

Chernysh M.F., Epikhina Yu.B. (eds.) (2018) Multidimensional Social Mobility in Modern Russia. Monograph, Moscow: FNISTS RAN (in Russian).

Gimpelson V.E. (2019) Age and Wage: Stylized Facts and Russian Evidence. HSE Economic Journal, no 2, pp. 185-237 (in Russian). DOI: 10.17323/1813-8691-2019-23-2-185-237

Hillmert S., Jacob M. (2003) Social Inequality in Higher Education: Is Vocational Training a Pathway Leading to or Away from University? European Sociological Review, vol. 3, no 19, pp. 319-334. DOI: 10.1093/esr/19.3.319

Illich I. (2000) Deschooling Society, London: Marion Boyars.

Ilyin V.I. (2019) Social Surfing as a Model of Youth Lifestyle. Monitoring of Public Opinion: Economic and Social Changes, no 1(149), pp. 28-48 (in Russian). DOI: 10.14515/monitoring.2019.1.02

Johnson M., Elder G. (2002) Educational Pathways and Work Value Trajectories. Sociological Perspectives, vol. 45, no 2, pp. 113-138. DOI: 10.1525/sop.2002.45.2.113

Kapeliushnikov R.I. (2021) Returns to Education in Russia: Nowhere Lower? Preprint WP3/2021/03, Moscow: HSE (in Russian).

Karabel J. (1972) Community Colleges and Social Stratification. Harvard Educational Review, vol. 42, no 4, pp. 521-562. DOI: 10.17763/haer.42.4.46m282672517k642

Kasatkina N.P., Shumkova N.V. (2020) From Self-Education to Self-Employment: Back Entrance for Youth to the Labor Market. Monitoring of Public Opinion: Economic and Social Changes, no 3(157), pp. 201-223 (in Russian). DOI: 10.14515/monitoring.2020.3.1600

Konstantinovskiy D.L., Abramova M.A., Voznesenskaya E.D., Goncharova G.S., Kostyuk V.G., Popova E.S., Cherednichenko G.A. (2015) New Meanings in Educational Strategies of Youth: 50 Years of Research. Monograph, Moscow: TSSP i M (in Russian).

Konstantinovskiy D.L., Popova E.S. (2020) Vocational vs Higher Education. Mir Rossii, vol. 29, no 2, pp. 6-26 (in Russian). DOI: 10.17323/1811-038X-2020-29-2-6-26

Konstantinovskiy D.L., Vakhshtayn V.S., Kurakin D.Yu., Roshchina Y.M. (2006) Availability of Quality General Education: Opportunities and Limitations, Moscow: Logos (in Russian).

Konstantinovskiy D.L., Voznesenskaya E.D., Cherednichenko G.A. (2013) Working Youth Today: Education, Profession, Social well-Being. Sociological Science and Social Practice, vol. 0, no 2, pp. 21-38 (in Russian).

Kosyakova Yu., Yastrebov G.A., Yanbarisova D.M., Kurakin D.Yu. (2016) Reproduction of Social Inequality in the Russian Educational System. Zhurnal Sotsiologii i Sotsialnoy Antropologii (The Journal of Sociology and Social Anthropology), no 5(19), pp. 76-97 (in Russian).

McClelland D.C. (2010) The Achieving Society, Martino Publishing: Mansfield Centre.

Petukhov V.V. (2020) Russian Youth and Its Role in Society Transformation. Monitoring of Public Opinion: Economic and Social Changes, no 3, pp. 119-138 (in Russian). DOI: $10.14515 /$ monitoring.2020.3.1621

Qualitative Text Analysis: A Guide to Methods, Practice and Using Software (2013), SAGE Publications Ltd. 
Radaev V.V. (2018) Millennials Compared to Previous Generations: An Empirical Analysis. Sociological Studies, no 3, pp. 15-33 (in Russian). DOI: 10.7868/S0132162518030029

Radaev V.V. (2020) Divide among the Millennial Generation: Historical and Empirical Justifications. (Part two). Sotsiologicheskiy Zhurnal = Sociological Journal, vol. 26, no 4, pp. 31-60 (in Russian). DOI: 10.19181/socjour.2020.26.4.7641

Reznik Yu.M., Smirnov E.A. (2002) Personal Life Strategies (Experience of Complex Analysis), Moscow: Institut cheloveka RAN (in Russian).

Saganenko G.I., Stepantsova A.A., Stepanova E.I. (2015) Professional Preferences of Youth as an Indicator of Social Change. Vysshee Obrazovanie $v$ Rossii (Higher Education in Russia), no 2, pp. 59-70 (in Russian).

Semenova V.V., Chernysh M.F., Sushko P.E. (eds.) (2019) Social Mobility in an Increasingly Complex Society: Objective and Subjective Aspects. Monograph, Moscow: FNISTS RAN (in Russian).

Temnitskiy A.L. (2020) Formation of Individual Subjectivity in Labor among Young Workers in the Modern Russia. Monitoring of Public Opinion: Economic and Social Changes, no 3(157), pp. 182-200 (in Russian). DOI: 10.14515/monitoring.2020.3.1660

Yadova M.A. (2017) Educational and Professional Strategies of post-Soviet Youth. Russia and the Contemporary World, no 2(95), pp. 91-104 (in Russian). DOI: 10.31249/rsm/2017.02.06

Zubok Yu.A., Chuprov V.I. (2020) Youth Life Strategies: Implementation of Expectations and Social Moods. Monitoring of Public Opinion: Economic and Social Changes, no 3(157), pp. 13-41 (in Russian). DOI: 10.14515/monitoring.2020.3.1602 